\title{
Efficacy of Extended Ceftiofur Intramammary Therapy for Treatment of Subclinical Mastitis in Lactating Dairy Cows
}

\author{
S. P. Oliver, ${ }^{1}$ B. E. Gillespie, ${ }^{1}$ S. J. Headrick, ${ }^{1}$ H. Moorehead, ${ }^{1}$ P. Lunn, ${ }^{1}$ \\ H. H. Dowlen, ${ }^{1}$ D. L. Johnson, ${ }^{1}$ K. C. Lamar, ${ }^{1}$ S. T. Chester, ${ }^{2}$ and W. M. Moseley ${ }^{2}$ \\ ${ }^{1}$ Department of Animal Science and the Food Safety Center of Excellence, \\ The University of Tennessee, Knoxville 37996 \\ ${ }^{2}$ Pfizer Animal Health, Kalamazoo, Ml 49001
}

\section{ABSTRACT}

Little research has focused on treatment of cows with subclinical mastitis during lactation. Ceftiofur is a new broad-spectrum, third-generation cephalosporin antibiotic for veterinary use that inhibits bacterial cell wall synthesis by interfering with enzymes essential for peptidoglycan synthesis. Ceftiofur should be effective against a wide range of contagious and environmental mastitis pathogens. Objectives of the present study were to evaluate the efficacy of ceftiofur for treatment of subclinical mastitis in lactating dairy cows, and to determine if extended therapy regimens enhanced efficacy of ceftiofur. Holstein and Jersey dairy cows ( $\mathrm{n}=$ 88) from 3 dairy research herds were used. Cows were enrolled in the study based on milk somatic cell counts $>400,000 / \mathrm{mL}$ and isolation of the same mastitis pathogen in 2 samples obtained 1 wk apart. Cows with one or more intramammary infections (IMI) were blocked by parity and DIM and allocated randomly to 1 of 3 different ceftiofur treatment regimens: $2-\mathrm{d}(\mathrm{n}=49 \mathrm{IMI})$, 5 -d ( $\mathrm{n}=41 \mathrm{IMI}$ ), and 8-d ( $\mathrm{n}=38 \mathrm{IMI})$ treatment regimens. For all groups, $125 \mathrm{mg}$ of ceftiofur hydrochloride was administered via intramammary infusion. Eighteen cows with 38 IMI were included as an untreated negative control group. A bacteriological cure was defined as a treated infected mammary quarter that was bacteriologically negative for the presence of previously identified bacteria at 14 and $28 \mathrm{~d}$ after the last treatment. Efficacy of ceftiofur therapy against all subclinical IMI was $38.8,53.7$, and $65.8 \%$ for the $2-, 5-$, and 8 $\mathrm{d}$ ceftiofur treatment regimens, respectively. Four of 38 (10.5\%) IMI in control cows were cured spontaneously without treatment. All 3 ceftiofur treatment regimens were significantly better than the negative control, and the 8-d extended ceftiofur treatment regimen treatment group was significantly better than the standard 2-d treatment group. Pathogen groups had significantly dif-

Received January 30, 2004.

Accepted April 2, 2004

Corresponding author: S. P. Oliver; e-mail: soliver@utk.edu. ferent cure rates from one another. The cure rate for the 8-d extended ceftiofur treatment regimen was $70 \%$ for Corynebacterium bovis, $86 \%$ for coagulase-negative Staphylococcus species, $36 \%$ for Staph. aureus, $80 \%$ for Streptococcus dysgalactiae ssp. dysgalactiae, and $67 \%$ for Strep. uberis.

(Key words: mastitis, Streptococcus uberis, ceftiofur, extended therapy)

\section{INTRODUCTION}

Mastitis is an inflammation of the udder that affects a high proportion of dairy cows throughout the world. Clinical and subclinical mastitis are the 2 major forms of the disease. Clinical mastitis results in alterations in milk composition and appearance, decreased milk production, elevated body temperature, and swelling, redness, or heat in infected mammary quarters. It is readily apparent and easily detected. However, detection of mammary quarters with subclinical mastitis is more difficult because signs are not readily apparent. Consequently, subclinical mastitis, which is the most prevalent form of the disease, often goes undetected. Many subclinical IMI tend to persist, resulting in an elevated milk SCC and decreased milk production, which may lead to development of clinical mastitis and the opportunity for certain mastitis pathogens to spread from infected mammary quarters to uninfected mammary quarters.

In addition to the different forms of the disease, several diverse mastitis pathogens are able to invade the mammary gland, multiply there, and produce harmful substances that result in an inflammatory response. Mastitis pathogens are categorized as either contagious or environmental. Contagious pathogens live and multiply on and in the cow's mammary gland and are spread from cow to cow primarily during milking. Contagious pathogens include: Staphylococcus aureus, Streptococcus agalactiae, Mycoplasma species, and Corynebacterium bovis (Smith, 1983; Bramley and Dodd, 1984). Environmental pathogens reside in the environment where cows live. The most frequently isolated environ- 
mental pathogens are streptococci other than Strep. agalactiae, commonly referred to as environmental streptococci, and gram-negative bacteria (Bramley and Dodd, 1984; Smith et al., 1985). Environmental Streptococcus species involved in bovine mastitis include Strep. uberis, Strep. dysgalactiae ssp. dysgalactiae, Strep. equinus, Strep. equi, and the Enterococcus species (Oliver et al., 1997; Watts, 1988). Among the environmental streptococci, Strep. uberis appears to be the most prevalent (Hillerton et al., 1995; Oliver et al., 1997; Jayarao et al., 1999). Gram-negative bacteria involved in bovine mastitis include Escherichia coli, Klebsiella pneumoniae, K. oxytoca, Enterobacter spp. and Citrobacter spp. Among the gram-negative mastitis pathogens, $E$. coli and Klebsiella spp. appear to be the most prevalent (Hogan et al., 1999).

Acceptance and application of mastitis control programs implemented in the $1960 \mathrm{~s}$, including teat disinfection, antibiotic therapy, and culling of chronically infected cows, has led to considerable progress in controlling contagious mastitis pathogens. However, postmilking teat disinfection and antibiotic dry cow therapy is less effective against environmental mastitis pathogens. Studies have shown that as the prevalence of contagious mastitis pathogens is reduced, the proportion of IMI by environmental pathogens increases (Smith, 1983; Bramley and Dodd, 1984; Smith et al., 1985). Therefore, environmental mastitis has become a major problem in many well-managed dairy farms that have successfully controlled contagious pathogens (Oliver et al., 1997; Jayarao et al., 1999).

Ceftiofur is a new broad-spectrum, third-generation cephalosporin antibiotic for veterinary use. Ceftiofur inhibits bacterial cell wall synthesis by interfering with enzymes essential for peptidoglycan synthesis, which results in lysis of the bacterial cell and accounts for the bactericidal nature of this antibiotic (Hornish and Kotarski, 2002). Consequently, ceftiofur should be effective against a wide range of contagious and environmental mastitis pathogens.

To date, little research has focused on treatment of cows with subclinical mastitis during lactation. One objective of the present study was to evaluate efficacy of ceftiofur for treatment of naturally occurring subclinical mastitis in lactating dairy cows caused by a variety of mastitis pathogens. Another objective was to determine if extended ceftiofur therapy regimens for subclinical mastitis enhanced efficacy based on recent reports that have shown that lengthening treatment duration enhanced antibiotic efficacy (Deluyker et al., 2000; Gillespie et al., 2002; Oliver et al., 2003).

\section{MATERIALS AND METHODS}

Lactating dairy cows from 3 dairy research herds (The University of Tennessee Middle Tennessee Experi- ment Station, Spring Hill, TN; Dairy Experiment Station, Lewisburg, TN; and The University of Tennessee Knoxville Experiment Station, Knoxville, TN) were included in this study. All lactating cows in each herd with a milk SCC $\geq 400,000 / \mathrm{mL}$ based on Dairy Herd Improvement herd test data were considered for inclusion. Quarter foremilk samples from these cows were obtained for microbiological analysis on 2 occasions 1 wk apart. Cows $(n=88)$ were enrolled in the study based on milk SCC $>400,000 / \mathrm{mL}$ and isolation of the same mastitis pathogen in the 2 samples obtained 1 wk apart.

Infected cows in each herd were blocked by parity (1st and 2nd lactation, 3rd or greater lactation) and DIM ( $\leq 100,101$ to $200,>200)$, and allocated randomly to 1 of 4 treatment groups. Ceftiofur hydrochloride was formulated as an oil-based suspension in a plastet cannula designed for intramammary delivery (Pfizer Animal Health, Kalamazoo, MI). The manufacturer recommends infusion of one syringe of ceftiofur hydrochloride into each affected mammary quarter, which should be repeated at least once after a $24 \mathrm{~h}$ interval. Infected mammary quarters of cows in the standard 2-d ceftiofur treatment regimen group ( $\mathrm{n}=23$ infected cows, 49 IMI) were treated with $125 \mathrm{mg}$ of ceftiofur hydrochloride at 24-h intervals. Infected mammary quarters of cows in the 5 -d extended ceftiofur treatment regimen group ( $\mathrm{n}=$ 23 infected cows, 41 IMI) were treated once daily with $125 \mathrm{mg}$ of ceftiofur per quarter for 5 consecutive days. Infected mammary quarters of cows in the 8-d extended ceftiofur treatment regimen group $(n=24$ infected cows, 38 IMI) were treated once daily with $125 \mathrm{mg}$ of ceftiofur per quarter for 8 consecutive days. Eighteen cows with 38 IMI were included as an untreated negative control group. Infected mammary quarter(s) of each cow included in the study, except for cows in the untreated negative control group, were infused intramammarily with ceftiofur via full insertion of the plastet cannula into the teat end. Milk was discarded for $14 \mathrm{~d}$ from all cows in the study.

Mammary quarter foremilk samples were obtained 14 and $7 \mathrm{~d}$ before treatment, immediately prior to treatment, and 14 and $28 \mathrm{~d}$ after the last treatment for microbiological evaluation. All samples were collected immediately before regular milking using standard procedures described by the National Mastitis Council (Harmon et al., 1990; Hogan et al., 1999). Before sample collection, teats were dipped in a premilking teat disinfectant, cleaned thoroughly, dried with paper towels, and teat ends were sanitized with swabs containing $70 \%$ isopropyl alcohol.

Milk samples were examined following procedures recommended by the National Mastitis Council (Hogan et al., 1999) and as described by Oliver et al. (1994) 
with modifications. Briefly, foremilk samples $(10 \mu \mathrm{L})$ from each quarter were plated onto one quadrant of a trypticase soy agar plate supplemented with $5 \%$ defibrinated sheep blood. Plates were incubated at $37^{\circ} \mathrm{C}$ and bacterial growth was observed and recorded at 24$\mathrm{h}$ intervals for $3 \mathrm{~d}$. Bacteria on primary culture medium were identified tentatively according to colony morphologic features, hemolytic characteristics, and catalase test. Isolates identified presumptively as staphylococci were tested for coagulase by the tube coagulase method. Isolates identified presumptively as streptococci were evaluated initially for growth in $6.5 \% \mathrm{NaCl}$, hydrolysis of esculin, and Christie, Atkins, and Munch-Peterson (CAMP) reaction. Streptococci were identified to the species level using the API 20 Strep System (bioMerieux, Inc., Hazelwood, MO) upon initial isolation of the organism from infected mammary quarters. Streptococcal organisms isolated subsequently were identified by sodium hippurate hydrolysis for Strep. uberis, and a rapid latex test for streptococcal grouping (Streptex, Remel, Inc., Lenexa, KS) for Strep. dysgalactiae ssp. dysgalactiae. Bacteria identified presumptively as gram-negative were plated on MacConkey's agar (Becton Dickinson Microbiology Systems, Franklin Lakes, $\mathrm{NJ}$ ) and evaluated by the following biochemical tests: triple sugar iron, urea, oxidase, motility, indole, and ornithine decarboxylase. Gram-negative organisms were identified to the species level using the API $20 \mathrm{E}$ System (bioMerieux, Inc.) upon initial isolation of the organism from infected mammary quarters. Gram-negative organisms isolated subsequently were plated on MacConkey's agar and evaluated by the following biochemical tests: triple sugar iron, urea, oxidase, motility, indole, and ornithine decarboxylase.

The milk SCC was determined by the Dairy Herd Improvement Association Laboratory (Knoxville, TN). Milk samples $(\sim 25 \mathrm{~mL})$ for SCC determination were collected before cows were milked and after conducting the strip cup evaluation and collection of milk for microbiological evaluation.

A bacteriological cure was defined as an infection that was negative for the presence of previously identified bacteria at 14 and $28 \mathrm{~d}$ after last treatment. The percentage of subclinical IMI cured in mammary quarters receiving the standard 2-d therapy regimen was compared with mammary quarters receiving no treatment. The percentage of subclinical IMI cured in quarters receiving extended therapy regimens (5-d and 8-d) was compared with the percentage cured in the standard 2$d$ therapy regimen group and in untreated controls. The percentage of subclinical IMI cured by the 8-d extended therapy regimen was also compared with the percentage of subclinical IMI cured in the 5-d extended therapy regimen group.
Data were analyzed by multidimensional contingency table methodology, which compared cure rates between treatments by use of Pearson $\chi^{2}$ (release 8.02, SAS Inst., Inc., Cary, NC). Design factors, such as herds, cows, and pathogen groups, were examined to determine whether they could be eliminated and data pooled without a loss of information. For example, to test the hypothesis that there was no cow effect, a $\chi^{2}$ lack-of-fit test statistic was used to compare estimated cure rates with cows in the model against estimated cure rates with cows dropped from the model and their results summarized within each herd $\times$ treatment group. A significant lack-of-fit test result suggests that cows were different enough that collapsing across them resulted in lost information, whereas a nonsignificant lack-of-fit test means that there was no evidence that a cow contributed unique information, and thus no information was lost if results were combined across animals.

Contingency table analysis used for this study treated all factors as fixed except for the cure/fail response. This differed from approaches such as the generalized linear mixed models analysis, which considered herds, cows, and quarters-within-cows random effects. The fundamental difference between these 2 approaches had to do with inference. When herds were fixed, analysis results reflected only those herds and cows enrolled in the study and provided inference implicitly to comparable herds and cows outside the study. When herds were random, the analysis reflected the universe of herds and cows from which the experimental units came. However, the generalized linear mixed models analysis was a large sample analysis and its conclusions might not be reliable when data were as sparse as they were when analyzing separate pathogen/ pathogen groups. This was the primary reason for the methodology used.

The basic structure of data incorporated herds, treatments, cows within herds $\times$ treatments, quarters within cows, pathogens within quarters, and cure/fail responses of the pathogen infections within quarters. Of the 166 IMI identified in cows included in the study, only 11 quarters had more than one IMI per infected quarter; all other IMI had only one pathogen isolated from the infected mammary quarter. It was assumed that pathogen infections within a cow were independent of one another (i.e., the intracow correlation was negligible) and the cure/fail responses were defined at the cow level.

For a particular pathogen/pathogen group, the resulting 3 -factor contingency table was herd $\times$ treatment $\times$ response. To test whether there was a herd effect, a 2-step analysis was conducted. The first hypothesis tested was that there was no herd $\times$ treatment interac- 
tion. If this hypothesis was not significant, then the second hypothesis, that there was no herd effect, was tested. If the second hypothesis was not significant, then herds were conditionally independent of treatments. In this case, treatment by response information could be pooled over herds, and the Pearson $\chi^{2}$ statistic for 2-way tables was the appropriate statistic to compare treatments. When there was no herd $\times$ treatment interaction, but there was a significant herd effect, treatment comparisons needed to be made adjusting for herds. In this case, the Mantel-Haenszel $\chi^{2}$ statistic was used with herds as strata.

When there was a significant herd $\times$ treatment interaction, treatment differences were not always comparable across herds. Tests to analyze design effects included all 4 treatment groups. Thus, when there was a significant herd $\times$ treatment interaction, the strategy was to let the statistic used to compare each pair of treatments depend upon the nature of the herd effect for those 2 treatments alone. For each pair of treatments, the herd $\times$ treatment interaction and herd effect were tested. If neither was significant, then the Pearson $\chi^{2}$ statistic was used. If there was a significant herd effect but no herd $\times$ treatment interaction, then the Mantel-Haenszel $\chi^{2}$ statistic was used with herds as strata. When there was a significant herd $\times$ treatment interaction for the 2 treatments, the Pearson $\chi^{2}$ statistic was used to compare them.

In one analysis, the underlying model included not only herds, treatments, and responses, but also pathogen groups. In this case, the analysis of what effect these design factors had was determined using a backwards stepwise approach, starting with the full model including all the terms, and sequentially dropping factors (Agresti, 1990).

The significance level used depended upon the test. For pairwise treatment comparisons, a (one-sided) $5 \%$ significance level was used. For testing design factors (herds and pathogen groups along with their interactions), the Bonferroni adjustment was used to keep the overall type I error at $10 \%$. Thus, when herd was the only design factor, since testing the herd effect required 2 tests, each test was conducted at a $0.10 / 2=0.05$ significance level. When both herd and pathogen group were factors in the model, each test was conducted at a $0.10 / 5=0.02$ significance level since there were 5 tests or steps in the backwards stepwise algorithm to analyze the design effect.

\section{RESULTS}

There were 166 subclinical IMI in the 88 cows enrolled in this study. Most subclinical IMI were due to Staph. aureus, Corynebacterium bovis, CNS and Strep-
Table 1. Distribution of pathogens causing subclinical mastitis across herds. ${ }^{1}$

\begin{tabular}{lrrrr}
\hline & \multicolumn{3}{c}{ Herd } & \\
\cline { 2 - 4 } Pathogen & \multicolumn{1}{c}{ A } & \multicolumn{1}{c}{ B } & \multicolumn{1}{c}{ C } & Total \\
\hline Corynebacterium bovis & 1 & 0 & 36 & 37 \\
CNS $^{2}$ & 12 & 13 & 8 & 33 \\
Staphylococcus aureus $_{\text {Streptococcus dysgalactiae }}$ & 18 & 27 & 5 & 50 \\
Streptococcus uberis $^{\text {Other environmentals }}{ }^{3}$ & 5 & 8 & 1 & 14 \\
Other $^{4}$ & 2 & 3 & 15 & 20 \\
Total $^{4}$ & 2 & 4 & 1 & 5 \\
& 40 & 58 & 68 & 166 \\
\hline
\end{tabular}

${ }^{1}$ Mastitis pathogens causing $>10$ infections were listed separately. Otherwise pathogens were grouped.

${ }^{2}$ Coagulase-negative Staphylococcus species.

${ }^{3}$ Enterococcus faecalis, Enterococcus faecium, and Aerococcus viridans.

${ }^{4}$ Bacillus species, Corynebacterium species, Enterobacter cloacae, Escherichia coli, Nocardia species, Klebsiella oxytoca, and yeast.

tococcus species (Table 1 ). If a mastitis pathogen caused 10 or more infections, they were listed separately. Otherwise, pathogens were pooled with other infrequently isolated pathogens.

The first data analysis compared treatments over all subclinical IMI (Table 2). Efficacy of ceftiofur therapy against all subclinical IMI was 38.8, 53.7, and $65.8 \%$ for the 2-, 5-, and 8-d ceftiofur treatment regimens, respectively. All 3 ceftiofur treatment regimens were significantly better than the negative control, and the 8-d extended ceftiofur treatment regimen treatment group was significantly better than the standard 2-d treatment group. Since there was no herd $\times$ treatment interaction, the listed cure rates were representative of the 3 herds used in this study.

In the first analysis (Table 2), there was no differentiation among infections for the pathogen causing the infection. In the second analysis, pairwise comparison of the different treatment regimens over all infections adjusting for pathogen/pathogen group was performed. When pathogen/pathogen group was put in the model as strata, all 3 ceftiofur treatment regimens were significantly better than the negative control, and both the 5- and 8-d ceftiofur extended therapy treatment regimens had significantly higher bacterial cure rates than the standard 2-d ceftiofur treatment regimen (Table 3). Pathogen groups had significantly different cure rates from one another.

It was also of interest to investigate treatment differences with respect to each pathogen/pathogen group separately. Results of subclinical mastitis cure rates and pairwise comparisons among treatments for $C$. bovis, CNS, Staph. aureus, Strep. dysgalactiae ssp. dysgalactiae, Strep. uberis, and the combined environmental streptococci are shown in Table 4. Pathogen groups 
Table 2. Pairwise comparison of subclinical mastitis cure rates following different ceftiofur treatment regimens. ${ }^{1}$

\begin{tabular}{lrlrrr}
\hline & & \multicolumn{3}{c}{$P$-values $^{3}$} \\
\cline { 3 - 6 } Ceftiofur treatment regimen & Cured $(\%)^{2}$ & $2 \mathrm{~d}$ & $5 \mathrm{~d}$ & $8 \mathrm{~d}$ & Control \\
\hline $2 \mathrm{~d}$ & $19 / 49(39 \%)$ & $\ldots$ & 0.079 & 0.006 & 0.002 \\
$5 \mathrm{~d}$ & $22 / 41(54 \%)$ & 0.079 & $\ldots$ & 0.136 & $<0.001$ \\
$8 \mathrm{~d}$ & $25 / 38(66 \%)$ & 0.006 & 0.136 & $\ldots$ & $<0.001$ \\
Negative control & $4 / 38(11 \%)$ & 0.002 & $<0.001$ & $<0.001$ & $\ldots$ \\
\hline
\end{tabular}

${ }^{1}$ Data were analyzed using PROC FREQ and PROC GENMOD of SAS (version 8.2, SAS Inst., Inc., Cary, NC). Herds were conditionally independent of treatments. $(P=0.315$ for test of no herd by treatment interaction with 6 degrees of freedom, and $P=0.071$ for the test of no herd effect with $2 \mathrm{df}$. Each test used $\alpha=0.05)$. Treatments were compared using Pearson $\chi^{2}$ statistic.

${ }^{2}$ Number of cured infections divided by total number of infections.

${ }^{3}$ One-sided $P$-value comparing treatment listed in row with treatment listed in the column.

had significantly different cure rates from one another. None of the treatments was different from one another for Strep. uberis. The 2-d standard ceftiofur therapy treatment regimen was significantly greater than the negative control for C. bovis and Strep. dysgalactiae ssp. dysgalactiae. For all other pathogen/pathogen groups, the 8-d ceftiofur extended therapy treatment regimen was significantly better than the negative control, and except for Staph. aureus, the 5-d ceftiofur extended therapy treatment regimen was significantly greater than the negative control as well. The cure rate for Staph. aureus was $36 \%$ in the 8-d ceftiofur extended therapy treatment regimen and considerably less in the other ceftiofur treatment regimens. When all of the environmental Streptococcus species were grouped together, the 5- and 8-d ceftiofur extended therapy treatment regimens were significantly greater than the negative control but not different from the 2-d standard ceftiofur therapy treatment regimen.

\section{DISCUSSION}

Efficacy of ceftiofur therapy against all subclinical IMI was $38.8,53.7$, and $65.8 \%$ for the $2-, 5-$, and 8-d ceftiofur treatment regimens, respectively. Significant differences in efficacy were detected between all ceftiofur treatment regimens and the untreated negative control group, and between the 8-d ceftiofur extended therapy group and the standard 2-d treatment group. When pathogen/pathogen group was put in the statistical model, all 3 ceftiofur treatment regimens were significantly better than the negative control, and both the 5-d and 8-d ceftiofur extended therapy treatment regimens had significantly higher bacterial cure rates than the standard 2-d ceftiofur treatment regimen. Results of this study indicate that ceftiofur therapy was effective in eliminating subclinical IMI in lactating dairy cows caused by several different mastitis pathogens, and that extended ceftiofur therapy significantly enhanced treatment efficacy.

Table 3. Pairwise comparisons of different ceftiofur treatment regimens over all subclinical infections adjusting for pathogens groups. ${ }^{1,2}$

\begin{tabular}{lccccr}
\hline & & \multicolumn{4}{c}{$P$-values $^{4}$} \\
\cline { 3 - 6 } Ceftiofur treatment regimen & Cured $(\%)^{3}$ & $2 \mathrm{~d}$ & $5 \mathrm{~d}$ & $8 \mathrm{~d}$ & Control \\
\hline $2 \mathrm{~d}$ & $19 / 49(39 \%)$ & $\ldots$ & 0.035 & 0.005 & 0.002 \\
$5 \mathrm{~d}$ & $22 / 41(54 \%)$ & 0.035 & $\ldots$ & 0.216 & $<0.001$ \\
$8 \mathrm{~d}$ & $25 / 38(66 \%)$ & 0.005 & 0.216 & $\ldots$ & $<0.001$ \\
Negative control & $4 / 38(11 \%)$ & 0.002 & $<0.001$ & $<0.001$ & $\ldots$ \\
\hline
\end{tabular}

${ }^{1}$ Pathogen groups were C. bovis, S. aureus, CNS, S. uberis, environmentals (including S. dysgalactiae ssp. dysgalactiae), and "other" (refer to Table 1).

${ }^{2}$ Data were analyzed using PROC FREQ and PROC GENMOD of SAS (version 8.2, SAS Inst., Inc., Cary, NC). The full model consisted of herds by treatments by pathogens by response. The backwards stepwise hierarchical test series showed that herds were conditionally independent of treatments, but that there was a significant pathogen group effect $(P=0.310, P=0.035, P=0.033, P=0.225$, and $P<0.001$ for the test of no herd $\times$ group $\times$ treatment interaction, no herd $\times$ treatment or herd $\times$ group interactions, no herd effect, no group $\times$ treatment interaction, and no group effect, respectively, associated with $9,15,2,15$, and $5 \mathrm{df}$, respectively. Each test used $\alpha=0.02$ ). Treatments were compared using the Mantel-Haenszel statistic with pathogen groups as strata.

${ }^{3}$ Number of cured infections divided by total number of infections.

${ }^{4}$ One-sided $P$-value comparing treatment listed in row with treatment listed in the column. 
Table 4. Subclinical mastitis cure rates and pairwise comparisons among different ceftiofur treatment regimens for pathogen groups. ${ }^{1}$

\begin{tabular}{|c|c|c|c|c|c|c|}
\hline $\begin{array}{l}\text { Ceftiofur treatment } \\
\text { regimen }\end{array}$ & C. bovis & CNS & $\begin{array}{l}\text { Pathogen } \\
\text { Staphylococcus } \\
\text { aureus }\end{array}$ & $\begin{array}{l}\text { Streptococcus } \\
\text { dysgalactiae }\end{array}$ & $\begin{array}{l}\text { Streptococcus } \\
\text { uberis }\end{array}$ & $\begin{array}{l}\text { Environmental } \\
\text { Streptococci }^{5}\end{array}$ \\
\hline $2 \mathrm{~d}$ & $4 / 10(40 \%)^{\mathrm{a}}$ & $7 / 10(70 \%)^{a b}$ & $1 / 15(7 \%)^{\mathrm{a}}$ & $3 / 4(75 \%)^{\mathrm{a}}$ & $1 / 6(17 \%)^{\mathrm{a}}$ & $6 / 12(50 \%)^{\mathrm{ab}}$ \\
\hline $8 \mathrm{~d}$ & $7 / 10(70 \%)^{\mathrm{ab}}$ & $6 / 7(86 \%)^{\mathrm{a}}$ & $4 / 11(36 \%)^{b}$ & $4 / 5(80 \%)^{\mathrm{a}}$ & $2 / 3(67 \%)^{\mathrm{a}}$ & $7 / 9(78 \%)^{\mathrm{a}}$ \\
\hline Negative control & $0 / 14(0 \%)^{c}$ & $1 / 3(33 \%)^{b}$ & $0 / 12(0 \%)^{\mathrm{a}}$ & $0 / 3(0 \%)^{b}$ & $1 / 2(50 \%)^{\mathrm{a}}$ & $1 / 6(17 \%)^{b}$ \\
\hline
\end{tabular}

${ }^{1}$ For the analyses within individual pathogen groups, data were analyzed using PROC FREQ and PROC GENMOD of SAS (version 8.2, SAS Inst., Inc., Cary, NC). Herds and treatments were considered fixed effects.

${ }^{2}$ For each pathogen group, none of the tests of no cow $\times$ response interaction within herd $\times$ treatment was significant at the $10 \%$ significance level (results not shown). Thus, except for the environmental pathogen group, infections were pooled across cows within herd $\times$ treatment, creating a 3-way contingency table of herd $\times$ treatment $\times$ response. For the environmental pathogen group, infections were pooled across cows within herd $\times$ treatment $\times$ pathogen, creating a 4 -way contingency table. For Staph. aureus, Strep. dysgalactiae ssp. dysgalactiae, and Strep. uberis pathogen groups, treatments were conditionally independent of herds, thus treatments were compared using Pearson $\chi^{2}$. For the environmental pathogen group, treatments were conditionally independent of both herds and pathogen groups, so treatments were compared using Pearson $\chi^{2}$. For the CNS pathogen group, there was a significant herd $\times$ treatment interaction so the form of the test (Pearson $\chi^{2}$ or Mantel-Haenszel) depended upon the herd $\times$ treatment interaction for each pair being tested. Finally, for the Corynebacterium bovis pathogen group, there were too few infections in one herd so that no herd effect could be tested. Treatments were compared using Pearson $\chi^{2}$ statistic.

${ }^{3}$ Number of infections cured divided by total number of infections.

${ }^{4}$ Percentages with different letters are significantly different from one another at the (one-sided) $5 \%$ level.

${ }^{5}$ Includes Strep. dysgalactiae ssp. dysgalactiae, Strep. uberis, Enterococcus faecalis, Enterococcus faecium, and Aerococcus viridans.

In the present study, 2 different analyses that involved all infections were conducted. Because this study used naturally occurring subclinical IMI, the observed distribution of infections over all pathogens was assumed to be representative of the actual underlying population. Thus, these analyses provided information on efficacy of treatments used on subclinical mastitis when nothing was known about the underlying infection. Each analysis provided different information. The first analysis summarized in Table 2 provided information about how one treatment would do on one infection compared with another treatment on a second infection. The second analysis (Table 3 ) adjusted for the pathogen causing the infection. This meant that comparative cure rates reflected how they would perform on similar pathogens. By adjusting for the pathogen causing the infection, the second analysis most closely reflects the comparative efficacy one would expect to see in the field.

Gillespie et al. (2002) demonstrated that extended pirlimycin therapy was more effective in eliminating naturally occurring subclinical mastitis caused by environmental streptococci and Staph. aureus in lactating dairy cows than the standard 2-d treatment regimen. Overall efficacy of pirlimycin therapy against environmental streptococci and Staph. aureus was 44.4, 61.1, 95.0, and $0 \%$ for the 2-, 5-, and 8-d pirlimycin treatment regimens, and the untreated negative control group, respectively. Significant differences in efficacy were detected between all pirlimycin treatment regimens and the untreated negative control group, and between the 8-d pirlimycin extended therapy group and the standard 2-d treatment group. In the present study, signifi- cant differences in efficacy against all subclinical IMI were detected between all ceftiofur treatment regimens and the untreated negative control group, and between the 8-d ceftiofur extended therapy group and the standard 2-d treatment group similar to results observed by Gillespie et al. (2002).

A study conducted in Europe evaluated efficacy of pirlimycin for treatment of subclinical mastitis (Deluyker et al., 2000). In this study, cows either received no treatment or treatment with pirlimycin for $2 \mathrm{~d}$ or 8 d. A mammary quarter was considered not cured if a bacterial species cultured before treatment was isolated after treatment. Cure rates for subclinical Staph. aureus infections were $25 \%$ for the standard 2-d pirlimycin treatment group and $51 \%$ for the 8 -d pirlimycin extended therapy group. Cure rates for subclinical Staph. aureus infections in the standard 2-d ceftiofur treatment group observed in the present study were similar to the standard 2-d pirlimycin treatment group reported by Deluyker et al. (2000), however, efficacy of the 8-d ceftiofur treatment group was lower than that for the 8-d pirlimycin extended therapy group reported by Deluyker et al. (2000).

Deluyker et al. (2000) also evaluated efficacy of pirlimycin on intramammary infections with Strep. uberis and Strep. dysgalactiae ssp. dysgalactiae. Cure rates for Strep. uberis were $21 \%$ for 2 -d and $75 \%$ for 8 -d pirlimycin treatment regimens. Cure rates for Strep. dysgalactiae ssp. dysgalactiae were 69 and $100 \%$ for the 2-d and 8-d pirlimycin treatment regimens, similar to the $50,83.3$, and $100 \%$ for the $2-, 5$-, and 8-d pirlimycin treatment of Strep. uberis, and the 100, 83.3, 
and $100 \%$ for treatment of Strep. dysgalactiae ssp. dysgalactiae observed in the study by Gillespie et al. (2002). Efficacy of ceftiofur against Strep. dysgalactiae and all environmental Streptococcus species in the present study is consistent with that reported by Deluyker et al. (2000) and Gillespie et al. (2002) for pirlimycin.

In another study involving extended pirlimycin therapy, Owens et al. (1997) reported improved cure rates against chronic Staph. aureus IMI using an extended therapy regimen $(6 \mathrm{~d})$ when compared with conventional 2-d therapy according to the manufacturers' instructions. These researchers reported cure rates of 26 , $41.5,42$, and $86 \%$ for chronic Staph. aureus IMI in 4 dairy herds using the 6-d treatment protocol. In their study, the presence of one colony of Staph. aureus was considered positive for infection and therefore a treatment failure.

Results of our work (Gillespie et al., 2002; Oliver et al., 2003, 2004) and others (Owens et al., 1997; Deluyker et al., 2000) support the concept that extended therapy is significantly more effective at eliminating natural and experimentally induced IMI than is standard intramammary treatment. It would appear that lengthening the duration of antibiotic therapy increases treatment efficacy. This has been demonstrated for ceftiofur and pirlimycin against Strep. uberis, other environmental Streptococcus species, and Staph. aureus.

\section{CONCLUSIONS}

A study involving 166 IMI of 88 Holstein and Jersey cows was conducted to investigate the efficacy of extended ceftiofur therapy for treatment of subclinical mastitis in lactating dairy cows. A cure was defined as the pathogen isolated at enrollment not being present at 14 and $28 \mathrm{~d}$ after the last antibiotic infusion. Efficacy of ceftiofur therapy against all subclinical IMI was 38.8 , 53.7 , and $65.8 \%$ for the 2-, 5-, and 8-d ceftiofur treatment regimens, respectively. Four of the 38 (10.5\%) IMI in control cows were cured spontaneously without treatment. All 3 ceftiofur treatment regimens were significantly better than the negative control, and the 8-d extended ceftiofur treatment regimen treatment group was significantly better than the standard 2-d treatment group. When pathogen/pathogen group was put in the statistical model, all 3 ceftiofur treatment regimens were significantly better than the negative control, and both the 5-d and 8-d ceftiofur extended therapy treatment regimens had significantly higher bacterial cure rates than the standard 2-d ceftiofur treatment regimen. Pathogen groups had significantly different cure rates from one another. None of the treatments was different from one another for Strep. uberis. The 2-d standard ceftiofur therapy treatment regimen was sig- nificantly greater than the negative control for $C$. bovis and Strep. dysgalactiae ssp. dysgalactiae. For all other pathogen/pathogen groups, the 8-d ceftiofur extended therapy treatment regimen was significantly better than the negative control, and except for Staph. aureus, the 5-d ceftiofur extended therapy treatment regimen was significantly greater than the negative control as well. The cure rate for Staph. aureus was $36 \%$ in the 8-d ceftiofur extended therapy treatment regimen and considerably less with the other ceftiofur treatment regimens. When all of the environmental Streptococcus species were grouped together, the 5- and 8-d ceftiofur extended therapy treatment regimens were significantly greater than the negative control but not different from the 2-d standard ceftiofur therapy treatment regimen. Results of this study indicate that ceftiofur therapy was effective in eliminating subclinical IMI in lactating dairy cows caused by several different mastitis pathogens, and that extended ceftiofur therapy regimens significantly enhanced treatment efficacy.

\section{ACKNOWLEDGMENTS}

This investigation was supported by Pfizer Animal Health, the Tennessee Agricultural Experiment Station, The University of Tennessee Food Safety Center of Excellence, and The University of Tennessee, College of Veterinary Medicine, Center of Excellence Research Program in Livestock Diseases and Human Health.

\section{REFERENCES}

Agresti, A. 1990. Categorical Data Analysis. John Wiley \& Sons, New York.

Bramley, A. J., and F. H. Dodd. 1984. Reviews of the progress of dairy science: Mastitis control-progress and prospects. J. Dairy Res. 51:481-512.

Deluyker, H. A., P. Michanek, N. Wuyts, S. N. VanOye, and S. T. Chester. 2000. We treat sick cows don't we? The case of subclinical mastitis. Pages 170-174 in Proc. Natl. Mastitis Counc., Arlington, VA.

Gillespie, B. E., H. Moorehead, H. H. Dowlen, D. L. Johnson, K. C. Lamar, M. J. Lewis, S. J. Ivey, and S. P. Oliver. 2002. Efficacy of extended pirlimycin therapy for treatment of chronic environmental Streptococcus species intramammary infections in lactating dairy cows. Vet. Ther. 3:373-380.

Harmon, R. J., R. J. Eberhart, D. E. Jasper, B. E. Langlois, and R. A. Wilson. (eds). 1990. Microbiological Procedures for the Diagnosis of Bovine Udder Infection. 3rd ed. Natl. Mastitis Counc., Inc., Arlington, VA.

Hogan, J. S., R. Gonzalez, R. J. Harmon, S. C. Nickerson, S. P. Oliver, J. W. Pankey, and K. L. Smith. 1999. Laboratory Handbook on Bovine Mastitis. 1st ed. Natl. Mastitis Counc., Inc., Madison, WI.

Hillerton, J. E., A. J. Bramley, R. T. Shaker, and C. H. McKinnon. 1995. Patterns of intramammary infection and clinical mastitis over a 5 year period in a closely monitored herd applying mastitis control measures. J. Dairy Res. 62:39-50.

Hornish, R. E., and S. F. Kotarski. 2002. Cephalosporins in veterinary medicine-Ceftiofur use in food animals. Curr. Top. Med. Chem. 2:717-731. 
Jayarao, B. M., B. E. Gillespie, M. J. Lewis, H. H. Dowlen, and S. P. Oliver. 1999. Epidemiology of Streptococcus uberis intramammary infections in a dairy herd. J. Vet. Med. B. 46:433-442.

Oliver, S. P., L. F. Calvinho, and R. A. Almeida. 1997. Characteristics of environmental Streptococcus species involved in mastitis. Pages 1-35 in Proc. Symp. Udder Health Mgmt. for Environ. Streptococcus, Guelph, Ontario, Canada

Oliver, S. P., R. A. Almeida, B. E. Gillespie, S. J. Ivey, H. Moorehead, P. Lunn, H. H. Dowlen, D. L. Johnson, and K. C. Lamar. 2003. Efficacy of extended pirlimycin therapy for treatment of experimentally-induced Streptococcus uberis intramammary infections in lactating dairy cattle. Vet. Ther. 4:299-308.

Oliver, S. P., B. E. Gillespie, S. J. Ivey, H. Moorehead, P. Lunn, H. H. Dowlen, D. L. Johnson, K. C. Lamar, S. T. Chester, and W. M. Moseley. 2004. Extended ceftiofur therapy for treatment of experimentally-induced Streptococcus uberis mastitis in lactating dairy cattle J. Dairy Sci. (Accepted)
Oliver, S. P., B. E. Gillespie, M. J. Lewis, T. L. Ingle, and H. H. Dowlen. 1994. Evaluation of chlorhexidine as a premilking teat disinfectant for the prevention of intramammary infections during lactation. J. Food Prot. 57:614-618.

Owens, W. E., C. H. Ray, R. L. Boddie, and S. C. Nickerson. 1997. Efficacy of sequential intramammary antibiotic treatment against chronic $S$. aureus intramammary infections. Large Anim. Pract. 18:10-12.

Smith, K. L. 1983. Mastitis control: A discussion. J. Dairy Sci. 66:1790-1794.

Smith, K. L., D. A. Todhunter, and P. S. Schoenberger. 1985. Environmental mastitis: Cause, prevalence, prevention. J. Dairy Sci. 68:1531-1553.

Watts, J. L. 1988. Characterization and identification of streptococci isolated from bovine mammary glands. J. Dairy Sci. 71:16161624. 